\title{
O uso de um instrumento de política de saúde pública controverso: a eutanásia de cães contaminados por leishmaniose no Brasil
}

\author{
Use of an instrument of controversial public health policy: \\ euthanasia of dogs contaminated by leishmaniasis in Brazil
}

\section{Carlos José Saldanha Machado}

Fundação Oswaldo Cruz. Programa de Pós-Graduação em Biodiversidade e Saúde. Rio de Janeiro, RJ, Brasil.

Fundação Oswaldo Cruz. Programa de Pós-Graduação em Informação e Comunicação em Saúde Fiocruz. Rio de Janeiro, RJ, Brasil. Universidade do Estado do Rio de Janeiro. Programa de Pós-Graduação em Meio Ambiente. Rio de Janeiro, RJ, Brasil.

E-mail: saldanhaळfiocruz.br

\section{Erica Gaspar Silva}

Universidade do Estado do Rio de Janeiro. Programa de Pós- Graduação em Meio Ambiente. Rio de Janeiro, RJ, Brasil.

E-mail: ericagasparbioœgmail.com

\section{Rodrigo Machado Vilani}

Universidade Federal do Estado do Rio de Janeiro. Rio de Janeiro, RJ, Brasil.

Universidade Candido Mendes. Programa de Mestrado em Planejamento Regional e Gestão de Cidades. Campos dos Goytacazes, RJ, Brasil.

E-mail: r_vilaniळyahoo.com.br

\section{Correspondência}

Avenida Brasil, 4365, sala 206A (ICICT/Pavilhão Haity Moussatché), Manguinhos. Rio de Janeiro, RJ, Brasil. CEP 21040-360.

\section{Resumo}

A leishmaniose visceral é uma zoonose transmitida por vetor, de importância mundial, que envolve os cães como reservatórios. A "eliminação dos reservatórios" está prevista expressamente como medida de controle no Manual de Vigilância e Controle da Leishmaniose Visceral elaborado pela Secretaria de Vigilância em Saúde, órgão do Ministério da Saúde. Contudo, a eliminação de cães soropositivos no Brasil, usada para controlar a leishmaniose visceral, tem sido pouco efetiva. Este trabalho levanta questionamentos sobre esse instrumento de política nacional de saúde pública com base em evidências científicas atuais e análises do ordenamento jurídico brasileiro, realizadas a partir do princípio da precaução e do reconhecimento dos animais como seres sencientes. Conclui-se pela imediata suspensão e revisão da prática de extermínio animal em um Estado Constitucional de Direito, e a adoção de métodos preventivos e mais eficazes que garantam a saúde pública sem proporcionar elevados custos emocionais aos proprietários de cães e financeiros aos cofres públicos.

Palavras-chave: Saúde Pública; Leishmaniose; Eutanásia Animal; Direito Ambiental. 


\section{Abstract}

Visceral leishmaniasis is a zoonotic disease transmitted by a vector of global importance, which involves dogs as reservoirs. The "elimination of reservoirs" is specifically determined as a control measure in the Manual de Vigilância e Controle de Leishmaniose Visceral [Manual of Surveillance and Control of Visceral Leishmaniasis] published by the Department of Health Surveillance of the Brazilian Ministry of Health. However, the elimination of seropositive dogs in Brazil, used to control visceral leishmaniasis, has been ineffective. This paper raises questions about this national public health policy instrument based on current scientific evidence and analysis of the Brazilian law, held from the precautionary principle and the recognition of animals as sentient beings. It concludes that an immediate suspension and a review of animal extermination practice in the Brazilian Constitutional Rule of Law is needed and the adoption of preventive and more effective methods to ensure public health without providing either emotional costs to dog owners nor burdening the public budget.

Keywords: Public Health; Leishmaniasis; Animal Euthanasia; Environmental Law.

\section{Introdução}

Nas últimas quatro décadas, o desenvolvimento econômico do Brasil concorreu para alterar as interações entre homem, ambiente e processos biológicos (Machado, 2013). O perfil epidemiológico do território nacional (Machado, 2012, 2013) foi redesenhado pelo estabelecimento de um quadro endêmico de leishmaniose (Maia; Campino, 2011; Dujardin, 2005), sobretudo a visceral, uma zoonose transmitida por vetor de importância mundial (Claborn, 2014), que envolve os cães como reservatórios, i.e., espécies animais das quais um parasita depende para sua sobrevivência (Fausto; Beaver; Jung, 1973). A dispersão espaço-temporal dessa e de outras doenças infecto-parasitárias, como a malária, a dengue e a hantavirose, acompanha o rápido crescimento de megacidades com um alto fluxo populacional, o aumento da pobreza, as baixas condições sanitárias, o deslocamento do reservatório doméstico e a adaptação das espécies vetoras, entre outros fatores de risco (Claborn, 2014). Tais características são propícias à expansão e à adaptação de um patógeno a um novo nicho, em diferentes escalas, desde a local, passando pela regional e nacional, até a global (Machado, 2013).

Uma vez que as zoonoses podem ser definidas como processos em fluxo (Machado, 2013), as mudanças ambientais colocam-se, sem dúvida, entre as mais importantes forças motrizes para a emergência e reemergência dessas doenças (Fausto; Beaver; Jung, 1973; WHO, 2010; Ashford, 1996), que contam ainda com mudanças no uso da terra, mudanças climáticas, condições socioeconômicas e perda de biodiversidade como matrizes impulsionadoras à disseminação espaço-temporal dessas enfermidades, tanto nas populações humanas, com nas animais. Contudo, para além dos aspectos de natureza ecológica, processos de natureza política, jurídica e institucional também operam como forças motrizes de uma dinâmica com características transnacionais (Machado, 2012, 2013, 2014).

A realização de estudos transversais sobre as consequências das mudanças referidas anteriormente para a saúde pública se constitui em um grande desafio cognitivo para o trabalho científico, que é o 
de conhecer, analisar, propor e/ou atualizar soluções para as doenças infecto-parasitárias, emergentes e reemergentes, como a leishmaniose, doença não contagiosa que se apresenta com características clínicas e epidemiológicas diversas em cada área geográfica (Claborn, 2014; WHO, 2010). O desafio epistemológico reside na compreensão simultânea da dinâmica ecológica da emergência e reemergência das zoonoses e da ação do Poder Público para enfrentar um processo em fluxo em um território de dimensões continentais. Uma vez que nenhum campo de saber é suficientemente abrangente para compreender a totalidade do objeto de estudo, trata-se aqui de um trabalho de pesquisa que demanda o exercício de uma ciência socioambiental biocêntrica, cuja abordagem se caracteriza pela integração das perspectivas ecológica e epidemiológica das ciências sociais e jurídica (Machado, 2012, 2013, 2014). Essa ciência será aqui praticada por meio do estudo da eliminação, no Brasil, de cães soropositivos para leishmaniose visceral como forma do poder público controlar a doença. A "eliminação dos reservatórios" está prevista expressamente como medida de controle no Manual de Vigilância e Controle da Leishmaniose Visceral da Secretaria de Vigilância em Saúde/Ministério da Saúde (Brasil, 2014). Em um momento histórico transnacional de amparo legal dos animais domésticos e silvestres (Machado, C. J. S., 2013) e de intensa produção de conhecimentos científicos (Claborn, 2014), cabe se perguntar se as pesquisas científicas sobre leishmaniose e o ordenamento jurídico de um Estado Democrático de Direito, o brasileiro, autorizam a adoção da prática de extermínio de animais de estimação, como os cães soropositivos, ou se é necessária uma revisão desse instrumento de política pública por causa do elevado custo emocional para os proprietários desses animais e financeiro para os cofres públicos (Claborn, 2014). Se as políticas públicas no Brasil instituem direitos assegurados constitucionalmente (Machado, 2014), ou que se afirmam graças ao reconhecimento por parte da sociedade e/ou pelos poderes públicos enquanto novos direitos das pessoas, comunidades, coisas ou outros bens materiais ou imateriais, como explicar a adoção da eutanásia de cães soropositivos como instrumento de política de saúde pública? Se a Constituição é o conjunto de regras jurídicas que formam a norma fundamental de uma nação, aquela que ocupa o topo da pirâmide hierárquica do direito posto, vinculando todas as normas infralegais, então qualquer ato que desrespeite essa hierarquia dever ser considerado ilegal?

A fim de responder essas questões e contribuir para o aprimoramento das políticas públicas nacionais de saúde - uma vez que elas existem para resolver problemas que afetam as pessoas em sociedade (Machado, 2012, 2014) - optou-se pela pesquisa documental e análise de dados a partir de uma abordagem pautada em evidências científicas publicadas em artigos científicos, após avaliação e validação pelos pares dos princípios de Direito Ambiental relacionados ao uso de animais na sociedade brasileira. Sendo a leishmaniose uma doença parasitária diversa, com uma variedade de manifestações extensiva às Américas, Ásia, Europa e África, ocorrendo em ambientes que vão do deserto, passando pelas florestas tropicais, ilhas oceânicas e chegando a habitats urbanos, a literatura científica sobre essa doença expressa essa diversidade em vários idiomas, como português, árabe, francês e inglês. Nesse trabalho, o levantamento da literatura científica priorizou as bases PubMed e SciELO, identificando e escolhendo os artigos mais atuais, escritos em inglês e/ou em português, com foco no Brasil e nas relações entre saúde, ambiente e sociedade, e aqueles mais citados por esses artigos, em teses, dissertações e livros que analisam a leishmaniose visceral. O levantamento sobre a regulamentação brasileira da proteção da vida animal e da identificação dos princípios constitucionais que se intercorrelacionam e parametrizam o uso de animais foi feito por meio do acesso ao gigantesco material legislativo produzido no Brasil, reunido na Rede de Informação Jurídica e Legislativa ${ }^{1}$ (LexML), coordenada pelo Senado Federal.

Além dessa introdução e da conclusão, o artigo está dividido em três seções. Inicialmente é feita uma análise da ecologia da realidade complexa das leishmanioses na dinâmica da vida em sociedade, procurando sintetizar diversos fatores intervenientes à luz de conhecimentos científi-

http://www.lexml.gov.br 
cos atuais. Na terceira, os princípios do sistema jurídico-constitucional e a regulamentação do uso de animais são discutidos à luz das perspectivas do antropocentrismo e biocentrismo presentes no ordenamento jurídico brasileiro. Em seguida, as argumentações desenvolvidas anteriormente são aprofundadas por um raciocínio que amplia, inter-relaciona e problematiza diversos fatores intervenientes na configuração do fenômeno analisado. Finalmente, na conclusão são feitas considerações gerais e específicas voltadas para o aprimoramento da política nacional de saúde pública de combate à leishmaniose visceral, que faz uso do instrumento da eutanásia em cães contaminados.

\section{A ecologia da realidade complexa das leishmanioses}

Leishmanioses são infecções causadas por protozoários parasitos intracelulares obrigatórios pertencentes à ordem Kinetoplastida, família Trypanosomatide, gênero Leishmaniose. Eles configuram um quadro clínico e epidemiológico vasto, englobando inúmeras espécies de leishmaniose que podem infectar o ser humano, entre outros mamíferos hospedeiros, figurando-se como um importante problema de saúde pública. Particularmente no Brasil, são relatados entre 2000-3000 casos por ano (Quinnell, 2009). Aqui, as leishmanioses estão incluídas no Sistema Nacional de Informação de Doenças de Notificação Compulsória do Ministério da Saúde, com registros de casos em todas as Unidades Federadas, afetando principalmente as populações mais pobres.

A leishmaniose visceral (doravante, LV) ganha cada vez mais destaque por causa da sua frequência de ocorrência e sua capacidade de se espalhar rapidamente, sendo o parasita transmitido a partir de animais aos vetores e depois, a partir deles, para seres humanos (WHO, 2010).

Na maior parte das regiões endêmicas, as leishmanioses apresentam uma distribuição difusa, composta por pequenos focos de transmissão, sendo esta distribuição focal decorrente das condições microecológicas que afetam o vetor, o parasito e o hospedeiro reservatório (Dantas-Torres, 2007). Em virtude desse panorama, as doenças apresentam características diferentes em cada área de transmissão.

$\mathrm{Na}$ atualidade, as leishmanioses ocupam a $9^{\mathrm{a}}$ posição no ranking das doenças infecciosas prioritárias (WHO, 2012), porém é amplamente negligenciada em consequência da desconsideração do Poder Público de sua complexidade epidemiológica/ecológica e escassez de dados sobre a sua incidência e propagação.

A pobreza aumenta o risco de leishmaniose. Casas com aglomeração de pessoas e sem condições sanitárias adequadas, criação de animais em regime de subsistência no peridomicílio e mata residual favorecem a dispersão do vetor e sua proximidade ao ser humano (WHO, 2012; Dantas-Torres, 2007). Outro fator que interfere na suscetibilidade das populações às leishmanioses é o estado nutricional do indivíduo. É sabido que condições de pobreza associada a dietas deficientes de proteína, ferro, vitamina A e Zinco aumentam a probabilidade de manifestações clínicas (Dsjeux, 2001).

Os parasitos de leishmaniose apresentam uma grande heterogeneidade genética e ecletismo quanto às diferentes ordens de mamíferos que são capazes de infectar. Esse ecletismo resulta em uma epidemiologia complexa e peculiar de cada área de ocorrência de leishmaniose, na qual somente a detecção da infecção por leishmaniose em um mamífero não é suficiente para incriminá-lo como um reservatório (Chagas et al., 1938). Para tanto, é necessário demonstrar que a população de parasitos depende daquele mamífero especificamente para a manutenção de seu ciclo, o que requer extensivos mapeamentos ecológicos. Em geral, a incriminação completa e objetiva de um mamífero não é possível, e as considerações devem ser feitas baseadas em uma série de evidências, como a elevada abundância e grande proporção da biomassa local e a vida longa o suficiente para sobreviver a períodos sem transmissão, suscetibilidade à infecção pelo parasito por um longo período de tempo sem desenvolver doenças agudas e presença de parasitos na circulação periférica, onde estão disponíveis à infecção dos flebotomíneos (WHO, 2010; Ashford, 1996). Entre os mamíferos silvestres e sinantrópicos já encontrados com infecção natural por leishmaniose, podem ser citados os gambás e cuícas (Ordem Marsupia- 
lia); tatus, preguiças e tamanduás (Superordem Xenarthra); ratos e pacas (Ordem Rodentia); cães, lobos e raposas (Ordem Carnivora); gatos, onças, suçuaranas e quatis (Ordem Carnivora); macacos (Ordem Primata) e morcegos (Ordem Chiroptera) (WHO, 2010). Quanto aos animais domésticos, a infecção do cão doméstico (Canis familiaris) por $L$. (L.) infantum chagasi é bastante descrita na literatura, e sua importância na transmissão urbana da leishmaniose visceral é bem aceita, sendo discutida desde os primeiros estudos sobre a doença no Brasil (WHO, 2012; Ashford, 1996; Deane, 1956; Brandão-Filho et al., 2003). No entanto, apesar de já haver registros de infecção natural de cães por L. braziliensis (Aguilar et al., 1989; Madeira et al., 2003), sua importância na cadeia de transmissão da leishmaniose tegumentar americana (doravante LTA) ainda está em discussão. Outros animais domésticos também são alvos de estudos, como os equinos, que já foram apontados como possíveis reservatórios de LTA no peridomicílio (Aguilar et al., 1989) e as galinhas, que são importantes atrativos de flebotomíneos no ambiente peridomiciliar (WHO, 2010; Brasil, 2014). Dentro do padrão clássico de transmissão de LTA, torna-se difícil qualquer tipo de intervenção para controlar a doença, já que o ciclo é mantido em ambiente silvestre (Campbell-Lendrum et al., 2001).

A proximidade dos cães aos humanos e a coexistência da LV sugerem que o cão possa manter e ampliar ciclos instalados no peridomicílio e confirmam o papel do cão doméstico como principal reservatório LV no Brasil (Deane, 1956).

A partir desses estudos, os órgãos sanitários no Brasil aplicam medidas de interrupção do ciclo de transmissão focadas na identificação e eliminação de cães suspeitos. Contudo, dados científicos mostram que, apesar das diretrizes bem definidas do Programa de Controle das Leishmanioses (PCL), centradas no tratamento precoce dos casos humanos e diminuição dos riscos de transmissão a partir da eutanásia do reservatório doméstico infectado e controle químico dos vetores, ocorreu um aumento do impacto da doença na saúde pública nacional, apresentando uma média anual de 3.357 casos humanos e 236 óbitos, atingindo principalmente populações de baixa renda (Ferreira; Moraes, 2001).

\section{Os principios do sistema jurídico-constitucional e a regulamentação do uso de animais}

No ordenamento jurídico nacional, a tutela dos animais pode estar centrada, por um lado, naqueles considerados silvestres, dotados de função ecológica com o amparo constitucional, ou, com base em uma função econômica, os domésticos, que seguem os preceitos do Código Civil. Prevalece, sob essa ótica, que no direito pátrio apenas os seres humanos são sujeitos de direito, enquanto a fauna restringe-se a objeto de direito. Essa perspectiva civilista denota o acentuado antropocentrismo do ordenamento jurídico brasileiro (Toledo, 2012).

O artigo 225 da Constituição Federal é o núcleo do ordenamento jurídico-ambiental brasileiro. Apesar do texto ter interpretações que destacam a natureza antropocêntrica da tutela constitucional ambiental (Machado, P. A. L., 2013), persiste, também, um claro entendimento do caráter biocêntrico dos comandos constitucionais (Machado, P. A. L., 2013; Silva, 1994). No que interessa a essa discussão, a proteção dada aos animais submetidos à crueldade ilustra o biocentrismo constitucional.

Sustentar uma visão antropocêntrica da tutela ambiental significa, portanto, admitir uma mera relação de causalidade (utilitarista) entre a qualidade do meio ambiente e a vida humana. Mas não é essa a perspectiva do Direito Ambiental, de essência reformadora e modificadora, "que surge para rever e redimensionar conceitos que dispõem sobre a convivência das atividades sociais" (Derani, 2001). Para tanto, os princípios da prevenção e da precaução ocupam papel central em uma mudança no paradigma jurídico, por meio dos quais o Poder Público deve atuar preventivamente e com respaldo científico para proteger a vida em todas as suas formas, conforme objetivo constante da Política Nacional do Meio Ambiente (Lei no 6.938/81).

Em diversos países, como Áustria, Alemanha, Suíça e Estados Unidos, essa nova dogmática jurí- 
dica alçou os animais a sujeitos de direito em uma nova categoria de personagens jurídicos (Toledo, 2012; Dias, 2006). A interpretação dos dispositivos constitucionais e da legislação ambiental federal, como a Lei 9.605/98, que trata de crimes e sanções administrativas ambientais, conduzirá à conclusão apontada por Dias (2006) de equivalência entre os direitos da pessoa humana e dos animais, particularmente na proteção do direito à vida, ao livre desenvolvimento de sua espécie, da integridade de seu organismo e de seu corpo. 0 combate às diversas práticas que contribuem para o sofrimento dos animais tem vasto amparo na jurisprudência do Supremo Tribunal Federal contra brigas de galo (rinhas) e a farra do boi, afastando destas a natureza de manifestação cultural (Brasil, 1997, 2007). Os dispositivos legais, os princípios de Direito Ambiental e a jurisprudência analisada, em conjunto, criam uma atmosfera jurídica condizente com a existência de direitos por parte dos animais.

Esse entendimento, atualmente, está em discussão para se tornar expressamente aceito no ordenamento pátrio, conforme se pode observar nos objetivos de dois Projetos de Lei em trâmite na Câmara dos Deputados. O Projeto de Lei n ${ }^{0}$ 7.991/2014, que propõe alteração do Código Civil, visa à definição de uma personalidade jurídica sui generis para os animais, tornando-os "sujeitos de direitos fundamentais". O referido projeto encontra-se apensado ao Projeto de Lei $n^{0} 6.799 / 2013$ que, por sua vez, desconstrói a ótica civilista contida no artigo 82 do Código Civil, segundo a qual os animais são meros objetos de direito.

A prática da eutanásia permanece como instrumento que pode ser incorporado ao ordenamento jurídico infraconstitucional pelo Projeto de Lei ${ }^{\circ}$ 6.474/2013. Em seu texto, a medida extrema seria "permitida nos casos de males, doenças graves ou enfermidades infectocontagiosas incuráveis que coloquem em risco a saúde de pessoas ou de outros animais”. Contudo, a proposta legislativa procura limitar a atuação dos órgãos de controle de zoonoses, criando a figura jurídica do "resgate" do animal com enfermidade incurável por entidade de proteção dos animais. Define-se, assim, maior rigor na adoção de uma intervenção fatal, obrigando a existência de laudos conclusivos, como exige a jurisprudência dos diversos tribunais do país. Nesse sentido, o Tribunal de Justiça de Minas Gerais decidiu que "ainda que existente exame positivo para Leishmaniose Visceral Canina, a verificação da real condição do cão, ainda que urgente, deve ser apurada antes da determinação da medida extrema de sacrifício do animal" (Minas Gerais, 2013).

No item 7.3.1 "Eutanásia de cães do manual de vigilância e controle da leishmaniose visceral”, a eutanásia canina surge como medida "recomendada a todos os animais sororreagentes e/ou parasitológico positivo" (Brasil, 2014). Essa prática, conforme sustentada e estimulada pelo Ministério da Saúde, encontra duas resistências claras e de distintos Poderes da União: a) primeiramente, o Legislativo sinaliza, claramente, a opção por reconhecer os animais como seres sencientes, o que significa a ampliação da proteção jurídica no que se refere ao direito à vida dos animais; b) em segundo lugar, é preciso destacar a posição reiterada do Poder Judiciário em proteger os animais dos abusos humanos, como no caso das ditas manifestações culturais da farra do boi, e, especificamente, contra o sacrifício de animais acometidos pela LV.

Não parece haver dúvida quanto ao isolamento, neste quesito, do Executivo (ora representado pelo Ministério da Saúde) na compreensão sobre as melhores práticas governamentais para a manutenção da harmonia social, a garantia dos direitos sociais e da saúde pública. É preciso, portanto, que haja uma revisão na política pública aqui discutida para que esta seja colocada em consonância com o arcabouço jurídico-institucional do país. Não se trata apenas de mera concordância com a interpretação dos demais poderes, mas de obediência aos preceitos constitucionais violados pelo uso do sacrifício animal em larga escala como solução para a LV. Essa prática, em última análise, viola flagrantemente os princípios da prevenção e da precaução, além de estar presa a uma estrita interpretação antropocêntrica dos preceitos constitucionais que, reforce-se, vem sendo enfrentada por autores, legisladores e magistrados do país.

Ainda que não previsto tacitamente, tomando por base os preceitos constitucionais, os autores 
pesquisados, a jurisprudência nacional e a legislação ambiental em vigor, "podemos concluir que os animais são sujeitos de direitos e que seus direitos são deveres de todos os homens" (Dias, 2006). Percebemos que direitos fundamentais, como o direito à vida, começam a extrapolar a dimensão humana para alcançar um mínimo de eficácia no mundo real e, consequentemente, representar a expressão jurídica dos valores éticos de uma sociedade democrática, entre os quais a tutela dos direitos dos animais, silvestres e domésticos ganha relevo no Direito Ambiental brasileiro neste século XXI.

Pelo conjunto de argumentos científicos e jurídicos até aqui analisados, essa nos parece ser a leitura mais atual e holística do texto constitucional. E, assim sendo, não há espaço para a sustentação de políticas públicas que estejam contra os objetivos fundamentais do Estado Democrático de Direito. A adoção da eutanásia de cães soropositivos como instrumento central de política de saúde pública, defendida pelo Ministério da Saúde em seu Manual de Vigilância e Controle da Leishmaniose Visceral, afronta o reconhecimento dos animais como seres sencientes, ignorando melhores práticas assentadas em robustas evidências científicas e, consequentemente, em descompasso com o conjunto de normas e princípios que informam o Direito Ambiental brasileiro (como será detalhado na próxima seção). Em síntese, as medidas adotadas pelo Ministério da Saúde desrespeitam o preceito de constitucionalidade das ações governamentais e não encontram eco entre as medidas juridicamente aceitáveis para assegurar o direito ao meio ambiente ecologicamente equilibrado para as gerações presentes e futuras.

\section{Ampliando e inter-relacionando os diversos fatores intervenientes na configuração do fenômeno analisado}

Mudanças ambientais potencializam a emergência de zoonoses, o desmatamento altera as condições naturais dos habitats de hospedeiros silvestres e vetores (Machado, C. J. S., 2013), podendo estes se aproximarem do ambiente peridomiciliar (WHO, 2010; Brasil, 2014). O fato se agrava quando, no peridomicílio, encontram-se condições propícias para a criação de flebotomíneos, como áreas sombreadas e úmidas, abrigos de animais domésticos e árvores frutíferas. Com disponibilidade de criadouro, abrigo e fonte alimentar, é razoável acreditar que certas espécies de vetores adaptam-se bem ao ambiente antrópico e estabelecem um ciclo de transmissão peridomiciliar da doença (Ferreira; Moraes, 2011).

O protocolo padrão na detecção da doença se caracteriza pelo diagnóstico precoce e o tratamento adequado dos casos humanos. 0 emprego de inseticidas e medidas de saneamento do meio doméstico para a redução da densidade do vetor são medidas cautelares, previstas no Manual de Vigilância e Controle da Leishmaniose Visceral (Brasil, 2014), que ilustram a essência do princípio da prevenção no Direito Ambiental e deveriam ser privilegiadas e colocadas em prática com a completa extinção da eliminação dos reservatórios.

Estudos apontam que em Araçatuba (São Paulo) praticamente a metade das pessoas que perderam seus cães eutanasiados adquiriram novos cães posteriormente (Dantas-Torres, 2007; Andrade, 2006). Além disso, a renovação torna a população canina mais jovem e as implicações epidemiológicas desse fato incluem maior suscetibilidade a diferentes doenças, maior prolificidade e baixa resposta imunológica a diversas vacinas contra importantes enfermidades como a raiva (Andrade, 2006; Dye, 1996), por exemplo.

Um modelo matemático desenvolvido para avaliar as medidas de controle da LV já salientou que uma parcela de cães sacrificados é reposta pela população na tentativa de compensar a perda de seu animal de estimação, o que influencia negativamente o controle através da eutanásia de cães positivos (Dye, 1996; Jansen; Roque, 2010). Estudo longitudinal sobre a dinâmica populacional em área endêmica para LV (Jequié/BA) também conclui que a eutanásia de cães positivos, mesmo quando realizada com eficiência, não reduz a incidência da leishmaniose visceral canina (doravante, LVC) (Marcondes et al., 2011).

Tem sido postulado que a população canina 
em áreas endêmicas é provavelmente composta por quatro grupos: aqueles suscetíveis à doença, aqueles que se tornam suscetíveis latentes, aqueles resistentes ao flebotomíneo (assintomáticos) e aqueles infecciosos. Diante dessa realidade, estudos apontam que a remoção de cães soropositivos pode gerar um efeito contrário no controle da LV. Uma proporção desses cães infectados pode nunca se tornar infecciosa, mas estes animais podem ser substituídos por cachorros susceptíveis à infecção, já que vimos anteriormente que a população, de forma geral, repõe os cães eutanasiados. A incerteza que reside na gênese dessa prática configura um dos elementos centrais para a aplicação do princípio da precaução. Nesse caso, a correta adoção do referido princípio implicaria em postergar as ações de remoção/sacrifício dos cães até que haja certeza científica quanto à eficácia dessa prática e que não acarretará danos graves ou irreversíveis. Dados científicos comprovam que somente uma porcentagem (43\%) dos cães infectados torna-se infecciosa; no entanto, o controle orientado para esses cães exigiria um teste de diagnóstico específico para cães infectantes. São desconhecidos, entretanto, os fatores que determinam se um cão irá tornar-se infeccioso após estar contaminado por leishmaniose (Jansen; Roque, 2010).

Outro dado de realidade a ser aqui ressaltado diz respeito ao fato de um cão não ser o único agente reservatório. Supõe-se que quando raposas e gambás infectados alimentam-se perto de habitações humanas, contribuem para a transmissão do parasita a cães ou humanos, o que torna esses animais um importante reservatório peridoméstico.

Uma modelagem matemática sugere que os programas de abate falham em virtude da alta incidência de infecção e contágio, da insensibilidade do teste de diagnóstico para detecção de cães infecciosos e dos atrasos de tempo entre o diagnóstico e o abate (Dye, 1996). Os registros de saúde mostram que não há associação entre o abate generalizado de 176 mil cães soropositivos entre 1990 e 1997 - e a redução no número de casos humanos (Jansen; Roque, 2010).

Diferentes estudos revelaram que, em áreas endêmicas com elevada prevalência da infecção, a maioria dos cães é assintomática e fonte de infecção para os insetos vetores por causa do encontro de parasitos na pele (Cabral et al., 1998). A existência de animais assintomáticos, como também daqueles que apresentam sinais e sintomas sugestivos de outras doenças, dificulta o diagnóstico de LV (Jansen; Roque, 2010).

No Paraná, foram realizadas capturas de flebotomíneos antes e depois da reorganização de um peridomicílio, que consistiu em: redução do despejo de água e esgoto diretamente no solo por meio de encanamentos e criação de fossa séptica; reconstrução de abrigos de animais domésticos a uma distância de pelo menos 100 metros da residência; poda de árvores para aumentar a exposição do solo à luz solar e reduzir a umidade; remoção periódica de matéria orgânica do solo (folhas e frutas em decomposição, fezes de animais domésticos etc.). Os autores observaram uma redução da população de flebotomíneos em cerca de 90\% (Teodoro et al., 2004). Alguns anos depois, as características peridomiciliares retornaram às condições iniciais e a população de flebotomíneos voltou a crescer em $61 \%$. Outro exemplo de ações combinadas e eficazes foi em Minas Gerais, onde o uso concomitante de três métodos de controle - coleiras de permetrina, controle do vetor e campanhas de conscientização da população - foi capaz de reduzir significativamente os números de casos humanos e caninos (Dye, 1996).

Vários trabalhos têm avaliado a eficácia tópica de inseticidas na prevenção da transmissão da LV em populações caninas (Courtenay et al., 2002; Costa, 2011). Esses estudos se baseiam na teoria de que medidas preventivas como a conscientização da população sobre o problema, o reconhecimento, por parte da população, do risco pessoal de contração da doença e a adoção de medidas de controle do risco são mais eficazes que a eutanásia desses animais. As diversas evidências científicas existentes que indicam caminhos contrários ao adotado pelo Ministério da Saúde configuram elementos suficientes para que a eutanásia seja ao menos suspensa até que haja consenso técnico-científico para embasar a política pública de saúde que visa ao combate da LV. Postergar no tempo e no espaço a prática da eutanásia significa desobediência aos princípios de Direito Ambiental, mencionados anteriormente, 
e a falta de observância de melhores técnicas disponíveis, contrariando os ditames constitucionais da eficiência pública. Além desses aspectos científicos e jurídicos, a suspensão imediata das práticas de eutanásia se assenta sobre os preceitos éticos de respeito aos direitos dos seres sencientes.

As relações entre humanos e animais têm sido reconhecidas como benéficas para a saúde humana (Machado, 2012, 2013). Animais de estimação têm um papel de apoio emocional e social, principalmente para a população mais idosa. A morte compulsória desses animais, além de gerar um grande custo emocional, vai contra os valores constitucionais de bem-estar da vida animal.

A eutanásia é considerada uma prática ilegal segundo o Código Penal brasileiro, sendo sua regulamentação objeto de discussão no processo de tramitação do novo Código Penal, e vai de encontro aos princípios éticos da medicina humana praticada no Brasil. Porém, para não humanos, essa prática não se configura crime e é rotineiramente praticada em nome da saúde pública, à revelia da determinação constitucional, mesmo com evidências científicas validadas pelos pares, de livre acesso, como as descritas acima, comprovando a ineficácia desse método de extermínio.

Diversos trabalhos apontam para um método de uso combinado de estratégias no controle da leishmaniose em abandono da eutanásia (Marcondes et al., 2011; Courtenay et al., 2002; Costa, 2011). Merecem destaque aquelas que podem ser decisivas para a saúde pública no combate à leishmaniose: campanhas educativas que orientem a população no combate ao vetor; profilaxia das residências, com medidas de higiene; uso de coleiras com ativo de repelente para os cachorros; investimento em pesquisa para elaboração de vacinas; conscientização sobre o perigo da doença e medidas de combate à pobreza e à desnutrição. A importância do conhecimento dos proprietários de cães para a prevenção zoonótica da leishmaniose (Ferreira; Moraes, 2001) é insubstituível. Para a realização de inquérito sobre o conhecimento da população sobre a doença, um dos métodos qualitativos utilizados é a aplicação de questionários com apresentação de material informativo sobre a doença, objetivando a sensibilização sobre a doença e os desdobramentos relacionados a ela, incluindo a opinião dos entrevistados sobre a eutanásia dos cães soropositivos.

Outro fator importante nesse debate em prol de uma política pública sustentável é o título sorológico (Courtenay et al., 2002; Costa, 2011). Hoje em dia, o ponto de corte dessa titulação, para realizar a eutanásia nos animais, é de 1/40, conforme exige o Ministério da Saúde. No entanto, existe a possibilidade de ocorrer reação cruzada com outros parasitos no teste sorológico, o que exigiria outra prova parasitológica associada (Courtenay et al., 2002; Costa, 2011), tornando o método pouco confiável para nortear diretrizes de políticas públicas.

Apesar das evidências científicas contrárias à prática da eutanásia como medida eficaz para o combate à doença e, por consequência, de garantia da saúde pública, a Advocacia Geral da União (Brasil, 2012), em 2012, emitiu um parecer jurídico sustentando que as ações (eutanásia) promovidas para o controle da leishmaniose visceral, por parte do Ministério da Saúde, eram respaldadas por evidências científicas robustas. Contudo, da leitura do parecer, a robustez sustenta-se na opinião de um único especialista contratado pelo próprio Ministério da Saúde. Os elementos de convencimento adotados foram a expansão da doença no país e o seu grau de letalidade. Como conclusão, a Advocacia Geral da União defende "que a eutanásia dos cães infectados pela leishmaniose é medida que se impõe, sob pena de evidente e irreversível prejuízo ao interesse público (aqui representado pela saúde pública e vidas humanas) e caracteriza-se por ser: cientificamente respaldada, indispensável ao êxito das ações e razoável na ponderação dos interesses envolvidos" (Brasil, 2012).

O parecer, visto que pautado em uma opinião isolada, desconsiderou evidências científicas que já comprovaram que a estratégia de remoção de reservatórios é menos eficiente do que o controle dos vetores. Em uma simulação do impacto de diferentes estratégias sobre a transmissão da leishmaniose foi mostrado que a eliminação de reservatórios vertebrados é muito menos eficiente do que as vacinas, intervenções nutricionais ou o uso de inseticidas (Courtenay et al., 2002). 
A estrutura político-institucional vigente sustenta o Brasil como o único país do mundo com um programa de extermínio de cães em larga escala para controlar a LV (Costa, 2011). Ou seja, uma instância do Poder Executivo Federal institucionaliza ação contrária ao próprio ordenamento jurídico nacional que caminha para normatizar os animais como sujeitos de direito. Fica patente no país que a falta de consenso científico na escolha da melhor política de saúde para o controle da doença concorre para que se ignore ou se "interprete" mal a ciência disponível. Atualmente, uma medida legal para o reforço da política de abate de todos os animais soropositivos está sendo desenvolvido pelo Ministério da Saúde pela Assessoria Jurídica Brasileira Consultoria e Escritório (Parecer/CODELEGIS/ CONJUR/GABIN/MS/LP N 1243/2009). A perda de neutralidade durante a interpretação da informação científica que ocorreu dentro do próprio Estado foi provavelmente facilitada pelo fato da leishmaniose visceral zoonótica ser uma doença negligenciada, cujo controle atualizado, através de pesquisas sistemáticas, depende quase que inteiramente da burocracia do Estado em viabilizar ou retardar esse processo (Costa, 2011).

\section{Conclusões}

A Saúde Pública, como um dos campos de conhecimento, está voltada diretamente para a solução dos problemas da população humana e que a ela afetam, e suas relações com o ambiente do qual faz parte. Uma das maneiras de concretizar essas relações para tomar decisões melhor fundamentadas é pela informação publicada e disseminada, particularmente aquelas referentes às evidências científicas.

Assim, ao término deste trabalho, chega-se à conclusão de que a eutanásia, que deveria servir como instrumento para diminuir a ocorrência de uma doença emergente no Brasil, como a leishmaniose visceral, parece influenciar mais na estrutura da população canina do que no seu tamanho; as implicações epidemiológicas resultantes de uma população canina mais jovem podem ser graves. Portanto, programas de posse responsável de cães com enfoque na qualidade de vida dos animais, em consonância ao ordenamento jurídico do meio ambiente e os princípios de Direito Ambiental, configuram-se como mais adequados do que a técnica de controle populacional em áreas endêmicas para leishmaniose visceral.

Ao mesmo tempo, a identificação de características no peridomicílio das áreas estudadas, que são importantes para a manutenção do ciclo de vida do vetor, permite que medidas de manejo ambiental sejam alternativas viáveis para a redução do contato do vetor com o homem. Associadas a essas ações, a educação em saúde torna-se um bom instrumento preventivo de intervenção do Poder Público para orientar a população e reduzir a ocorrência de casos humanos de leishmaniose.

Evidências científicas demonstram que sacrificar cães não diminui a prevalência local de leishmaniose por causa de diversos fatores, como o fluxo constante de animais para a população com pouco manejo reprodutivo. A insistência na prática da eutanásia no Brasil, expressa no Manual de Vigilância e Controle da Leishmaniose Visceral do Ministério da Saúde, deflagra uma violação ao princípio da precaução, pautado na adoção de medidas cautelares com base científica. Ao postergar a revisão desta política pública de saúde, o Ministério da Saúde segue os preceitos constitucionais em vigor. A Constituição Federal visa a uma ampla tutela do ambiente natural que não pode ser limitada a uma perspectiva antropocêntrica e utilitarista de recursos naturais, da fauna e da flora. No século XXI, conforme se evidenciou, há vasto reconhecimento dos animais como seres sencientes, inclusive em projetos de lei tramitando na Câmara dos Deputados. A proteção dos animais pelo Legislativo e pelo Judiciário tem acompanhado os mais elevados preceitos éticos das sociedades contemporâneas. Esse reconhecimento deve, também, ser seguido pelo Poder Executivo por meio da extinção da prática da eutanásia de cães, não apenas por se configurar uma prática ilegal e sem amparo científico, mas por representar um desvio do Estado na sua missão de construir uma sociedade livre, justa e solidária. Com o sacrifício de um animal, muitas vezes está se retirando um cão que seria resistente e colocando no lugar outro 
com sistema imune sem nenhuma resistência (no caso dos filhotes), em um local com diversos vetores. Assim, o próprio Poder Público está contribuindo para o aumento da prevalência da doença no local. A eutanásia é cara, laboriosa e tem alta carga emocional para quem perde seu animal. Em vez de alocar recursos na realização de sacrifício animal, parte dessa verba poderia ser utilizada para um programa de política pública preventiva, substituindo a eutanásia por métodos de controle mais eficazes, condizentes com o ordenamento jurídico nacional e os princípios de direito ambiental. A prática oficial extensiva de extermínio de animais de estimação não é condizente com as evidências científicas atuais, os valores das ciências e da sociedade brasileira do século XXI (Machado, C. J. S. 2013).

\section{Referências}

AGUILAR, C. M. et al. Zoonotic cutaneous leishmaniasis due to Leishmania (Viannia) braziliensis associated with domestic animals in Venezuela and Brazil. Memórias do Instituto Oswaldo Cruz, Rio de Janeiro, v. 84, n. 1, p. 19-28, 1989.

ANDRADE, A. M. Dinâmica populacional canina na área urbana do município de Araçatuba, SP. 2006. Dissertação (Mestrado em Ciência Animal) Universidade Estadual Paulista, Araçatuba, 2006.

ASHFORD, R. W. Leishmaniasis reservoir and their significance in control. Clinics in Dermatology, New York, v. 14, n. 5, p. 523-532, 1996.

BRANDÃO-FILHO, S. P. et al. Wild and synanthropic hosts of Leishmania (Viannia) braziliensis in the endemic cutaneous leishmaniasis locality of Amaraji, Pernambuco, Brazil. Transactions of the Royal Society of Tropical Medicine and Hygiene, Oxford, v. 97, n. 3, p. 291-296, 2003.

BRASIL. Advocacia-Geral da União. Parecer $n^{o}$ 809/2012-AGU/CONJUR-MS/AVA. Eutanásia como política pública de controle da Leishmaniose Visceral, em cães infectados. Brasília, DF, 2012. Disponível em: <http://www.agu.gov.br/page/download/ index/id/23472018>. Acesso em: 14 out. 2015.

BRASIL. Ministério da Saúde. Secretaria de Vi- gilância em Saúde. Manual de Vigilância e Controle da Leishmaniose Visceral. Brasília, DF: Ministério da Saúde, 2014.

BRASIL. Supremo Tribunal Federal. Ação direta de inconstitucionalidade 3.776-5 Rio Grande do Norte. Brasília, DF, 14 jun. 2007. Disponível em: <http://redir.stf.jus.br/paginadorpub/paginador. jsp?docTP=AC\&docID=469712>. Acesso em: $11 \mathrm{fev}$. 2015.

BRASIL. Supremo Tribunal Federal. Recurso extraordinário n. 153.531-8 Santa Catarina. Brasília, DF, 3 jun. 1997. Disponível em: <http://redir.stf.jus.br/paginadorpub/paginador. jsp?docTP=AC\&docID=2115oor $>$. Acesso em: $11 \mathrm{fev}$. 2015.

CABRAL, M. et al. The immunology of canine leishmaniosis: strong evidence for a developing disease spectrum from asymptomatic dogs. Veterinary Parasitology, New York, v. 76, n. 3, p. 173-18o, 1998.

CAMPBELL-LENDRUM, D. et al. Domestic and peridomestic transmission of American cutaneous leishmaniasis: changing epidemiological patterns present new control opportunities. Memórias do Instituto Oswaldo Cruz, Rio de Janeiro, v. 96, n. 2, p. 159-162, 2001.

CHAGAS, E. et al. Leishmaniose visceral americana: relatório dos trabalhos realizados pela Comissão Encarregada do Estudo da Leishmaniose Visceral Americana em 1937. Memórias do Instituto Oswaldo Cruz, Rio de Janeiro, v. 33, n. 1, p. 89-229, 1938.

CLABORN, D. M. Leishmaniasis: trends in epidemiology, diagnosis and treatment. Rijeka: InTech, 2014.

COSTA, C. H. N. How effective is dog culling in controlling zoonotic visceral leishmaniasis? A critical evaluation of the science, politics and ethics behind this public health policy. Revista da Sociedade Brasileira de Medicina Tropical, Uberaba, v. 2, n. 44, p. 232-242, 2011.

COURTENAY, O. et al. Infectiousness in a cohort of brazilian dogs: why culling fails to control visceral leishmaniasis in areas of high transmission. Journal of Infectious Diseases, Oxford, v. 186, n. 9, p. 1314-1320, 2002.

DANTAS-TORRES, F. The role of dogs as reservoirs of Leishmania parasites, with emphasis on 
Leishmania (Leishmania) infantum and Leishmania (Viannia) braziliensis. Veterinary Parasitology, New York, v. 149, n. 3-4, p. 139-146, 2007.

DEANE, L. M. Leishmaniose visceral no Brasil. Rio de Janeiro: Serviço Nacional de Educação Sanitária, 1956.

DERANI, C. Direito ambiental econômico. São Paulo: Max Limonad, 2001.

DIAS, E. C. Os animais como sujeitos de direitos. Revista Brasileira de Direito Animal, Salvador, v. 1, n. 1, p. 119-121, 2006.

DSJEUX, P. The increase in risk factors for the leishmaniasis worldwide. Transactions of the Royal Society of Tropical Medicine and Hygiene, Oxford, v. 95, n. 14, p. 239-243, 2001.

DUJARDIN, J. C. Risk factors in the spread of leishmaniases: towards integrated monitoring? Trends in Parasitology, New York, v. 22, n. 1, p. 4-6, 2005.

DYE, C. The logic of visceral leishmaniasis control. American Journal of Tropical Medicine and Hygiene, Oakbrook Terrace, v. 55, n. 2, p. 125-130, 1996.

FAUSTO, E.; BEAVER, J.; JUNG, R. Animal agents and vectors of human diseases. Philadelphia: Lea \& Febiger, 1973.

FERREIRA, A. W.; MORAES, S. L. Diagnóstico laboratorial das principais doenças infecciosas e autoimunes. Rio de Janeiro: Guanabara Koogan, 2001.

JANSEN, A. M.; ROQUE, A. L. R. Domestic and wild mammalian reservoirs. In: TELLERIA, J.; TIBYARENC, M. (Ed.). American Trypanosomiasis: chagas disease. London: Elsevier, 2010. p. 249-276.

MACHADO, C. J. S. Ciências, políticas públicas e sociedade sustentável. Rio de Janeiro: E-Papers, 2012.

MACHADO, C. J. S. Animais na sociedade brasileira: práticas, relações e interdependências. Rio de Janeiro: E-Papers, 2013.

MACHADO, C. J. S. Desenvolvimento sustentável para o Antropoceno. Rio de Janeiro: E-Papers, 2014.

MACHADO, P. A. L. Direito ambiental brasileiro. São Paulo: Malheiros, 2013.
MADEIRA, M. F. et al. Leishmania (Viannia) braziliensis em cães naturalmente infectados. Revista da Sociedade Brasileira de Medicina Tropical, Uberaba, v. 36, n. 551, p. 5, 2003.

MAIA, C.; CAMPINO, L. Can domestic cats be considered reservoir hosts of zoonotic leishmaniasis? Trends in Parasitology, New York, v. 27, n. 8, p. 341-344, 2011.

MARCONDES, M. et al. Textbook of zoonoses: biology, clinical practice, and public health control. New York: Oxford University Press, 2011.

MINAS GERAIS. Tribunal de Justiça de Minas Gerais. Agravo de instrumento 10105130144535001 MG. Belo Horizonte, 2013. Disponível em: <http:// bit.ly/1zMmjfr >. Acesso em: 11 fev. 2015.

QUINNELL, R. J.; COURTENAY, O. Transmission reservoir host of zoonotic visceral leishmaniasis. $\mathrm{Pa}$ rasitology, Cambridge, v.136, n.14, p. 1915-1934, 2009.

SILVA, J. A. Direito ambiental constitucional. São Paulo: Malheiros, 1994.

TEODORO, U. et al. Reorganization and cleanness of peridomiciliar area to control sand flies (Diptera, Psychodidae, Phlebotominae) in South Brazil. Brazilian Archives of Biology and Technology, Curitiba, v. 47, n. 2, p. 205-212, 2004.

TOLEDO, M. I. V. A tutela jurídica dos animais no Brasil e no direito comparado. Revista Brasileira de Direito Animal, Salvador, v. 7, n. 11, p. 197-223, 2012.

WHO - WORLD HEALTH ORGANIZATION. Control of the leishmaniases: report of a meeting of the WHO Expert Committee on the Control of Leishmaniases. Geneva: WHO Press, 2010.

WHO - WORLD HEALTH ORGANIZATION. Research priorities for Chagas Disease, Human African Trypanosomiasis and Leishmaniasis. Geneva: WHO, 2012.

\section{Contribuição das autoras}

Machado e Silva foram responsáveis pela concepção do trabalho. Silva e Vilani realizaram a revisão bibliográfica e Vilani realizou a pesquisa jurisprudencial e legislativa. Machado orientou o trabalho. 